\title{
Las personas con discapacidad: ¿Los desempleados forzosos del capitalismo global?
}

People with disabilities: The forced unemployed of global capitalism?

Pessoas com deficiência: os desempregados forçados do capitalismo global?

Personnes handicapées: les chômeurs forcés du capitalisme mondial?

\section{Maximiliano Morales Martelli ${ }^{1}$ Universidad Nacional de La Plata}

Revista Derechos en Acción / ISSN 2525-1678 / e-ISSN 2525-1686

Año 4/Nº 10 Verano 2018/2019 (21 diciembre a 21 marzo), 161-177

DOl: https://doi.org/10.24215/25251678e248

ORCID: https://orcid.org/0000-0003-4867-3880

Recibido: 22/12/2018

Aprobado: 01/03/2019

Resumen: El presente trabajo se ocupará de analizar las relaciones de poder desarrolladas en el seno de la sociedad capitalista, y su responsabilidad en la exclusión del mercado laboral a la que se enfrentan las personas con discapacidad. Las consecuencias que tuvo, sobre este colectivo de trabajadores, la transición de una economía agraria y artesanal a una economía basada en la producción industrial y su consiguiente división técnica del trabajo. Asimismo, analiza la estigmatización de las personas con discapacidad como "no aptos" para el empleo; y el menoscabo producido por el desempleo inducido, como factor inherente a la economía capitalista.

Palabras claves: personas con discapacidad - capitalismo - desempleo - estigmatización

1 Abogado, Universidad Nacional de la Plata, Escuela de Abogados de la Administración Pública de la Provincia de Buenos Aires. 
Abstract: The present work will analyze the relations of power developed within the capitalist society, and its responsibility in the exclusion of the labor market that people with disabilities face. The consequences that the transition of an agrarian and artisan economy to an economy based on industrial production and its consequent technical division of labor had on this group of workers. It also analyzes the stigmatization of people with disabilities as "unfit" for work; and the detriment produced by induced unemployment, as an inherent factor in the capitalist economy.

Keywords: people with disability - capitalism - unemployment - stigmatization

Resumo: 0 presente trabalho analisará as relações de poder desenvolvidas dentro da sociedade capitalista, e sua responsabilidade na exclusão do mercado de trabalho que as pessoas com deficiência enfrentam. As consequências que teve, sobre esse coletivo de trabalhadores, a transição de uma economia agrária e artesanal a uma economia com base na produção industrial e sua consequente divisão técnica do trabalho. Da mesma forma, analisa a estigmatização das pessoas com deficiência como "não aptas" para o emprego; e o menoscabo produzido pelo desemprego induzido, como fator inerente à economia capitalista.

Palavras-chave: pessoas com deficiência - capitalismo - desemprego - estigmatização

Résumé: Le présent travail analysera les relations de pouvoir apparues au sein de la société capitaliste et sa responsabilité dans l'exclusion du marché du travail à laquelle font face les personnes handicapées. Les conséquences qu'a eu, sur ce collectif de travailleurs, le passage d'une économie agraire et artisanale à une économie basée sur la production industrielle et la division technique du travail qui en découle. II analyse également la stigmatisation des personnes handicapées comme "inaptes" à l'emploi; et produite par le chômage induit, comme facteur inhérent à l'économie capitaliste.

Mot-clés: personnes handicapées - capitalisme - chômage - stigmatisation 


\section{Introducción}

La Convención sobre los Derechos de las Personas con Discapacidad $^{2}$, aprobada por la Asamblea General de la Organización de las Naciones Unidas (ONU) el 13 de diciembre de 2006, con su preámbulo y sus cincuenta artículos, ha sido el primer Tratado Internacional de Derechos Humanos del siglo XXI. Significando un avance sustancial para "promover, proteger $y$ asegurar el goce pleno y en condiciones de igualdad de todos los derechos bumanos y libertades fundamentales por todas las personas con discapacidad, y promover el respeto de su dignidad inherente", tal como reza su primer artículo.

Para desarrollar el presente escrito me valdré de la definición de discapacidad acogida por la Convención:

La discapacidad es un concepto que evoluciona y que resulta de la interacción entre las personas con deficiencias y las barreras debidas a la actitud y al entorno que evitan su participación plena y efectiva en la sociedad, en igualdad de condiciones con las demás.

Tal como vemos, el acuerdo internacional retoma lo que Mike Oliver daría en llamar "modelo social de la discapacidad" (BARNES, C. 1998), surgido en el mundo anglosajón en torno a la Unión of Physically Impaired Against Segregation (UPIAS). Esta asociación fue fundada en el año 1974 por el activista Paul Hunt y el psicólogo Victor Finkelstein. De acuerdo a este modelo, la discapacidad no es causada por las limitaciones funcionales, físicas o psicológicas de las personas con insuficiencias, sino por el fracaso de la sociedad en suprimir las barreras y restricciones sociales que incapacitan. (UPIAS 1976; BARNES, C. 1998; FERRANTE, C. 2015).

Dialogando con la mamá de un niño con Síndrome de Down e integrante de una Asociaciones Civil que promueve la inclusión social de las personas con discapacidad, me expreso: "A todos lados voy así, con la Convención debajo del brazo."

2 En adelante Convención. 
No caben dudas del avance que representa la Convención en el plano normativo. Sin embargo, este progreso de ninguna manera tiene, a pesar de los años transcurridos desde su aprobación, un correlato equivalente en la experiencia diaria de este colectivo. Es evidente que el camino legal promovido por la Convención resulta exiguo para revertir la desigualdad sufrida por las personas con discapacidad.

El derecho a trabajar ha sido reconocido por la Convención en su Artículo 27, que afirma:

Los Estados Partes reconocen el Derecho de las Personas con Discapacidad a trabajar en igualdad de condiciones con los demás, ello incluye el derecho a tener la oportunidad de ganarse la vida mediante un trabajo libremente elegido o aceptado en un mercado laboral que sea abierto inclusivo y accesible.

En el mismo sentido se expresa la Convención Interamericana para la Eliminación de todas las formas de discriminación contra las Personas Con Discapacidad, la Declaración Universal de los Derechos Humanos, el Pacto Internacional de Derechos Económicos, Sociales y Culturales, el Pacto Internacional de Derechos Civiles y Políticos, y el Convenio de la Organización Internacional del Trabajo sobre la readaptación profesional y el empleo de las Personas Inválidas, entre otros.

A pesar de ello, se estima que las personas con discapacidad en edad de trabajar son alrededor de 785 millones en todo el mundo y alcanzan niveles de desempleo de hasta un $80 \%$ en algunos países (OMS y BANCO MUNDIAL 2011).

Evaluando especialmente la situación de Argentina, y tomando en consideración los datos ofrecidos por el último Censo realizado en el año 2010, podemos observar que existen alrededor de cinco millones de personas con discapacidad en nuestro país, lo que representa el $12,9 \%$ de la población total. De los cuales, cerca de tres millones forman parte de la población económicamente activa -tienen de 20 a 65 años(INDEC, 2010). 
Por su parte, la Encuesta Nacional de Personas con Discapacidad realizada entre los años 2002/2003 señala que sólo el $25 \%$ tiene empleo y que el $68,4 \%$ se encuentran inactivos (INDEC, 2002,2003). ${ }^{3}$

En este sentido, nuestra Constitución Nacional en su Artículo 75, Inc. 23, dispone que corresponde al Congreso:

Legislar y promover medidas de acción positiva que garanticen la igualdad real de oportunidades y de trato, y el pleno goce y ejercicio de los derechos reconocidos por esta Constitución y por los tratados internacionales vigentes sobre derechos humanos, en particular respecto de las personas con discapacidad.

En ejercicio de estas atribuciones, el Congreso ha sancionado la Ley $\mathrm{N}^{\circ} 25.689$, modificatoria de la Ley $\mathrm{N}^{\circ} 22.431$, estableciendo la obligación de los tres poderes del Estado -incluyendo organismos descentralizados o autárquicos, los entes públicos no estatales, las empresas del Estado y las empresas privadas concesionarias de servicios públicos- de ocupar personas con discapacidad que reúnan condiciones de idoneidad para el cargo, en una proporción no inferior al cuatro por ciento (4\%) de la totalidad de su personal. Sin embargo, el Estado Argentino incumple sistemáticamente esta normativa puesto que, desde su sanción, el cupo continuó por debajo del uno por ciento (1\%) (BLOGNA, T. 2016). De las 186 jurisdicciones ministeriales, organismos descentralizados $\mathrm{y}$ universidades nacionales correspondientes a la Administración Pública Nacional, solo nueve tuvieron empleados/as con discapacidad en una proporción del $4 \%$ o superior (CELS 2017).

Asimismo, mediante Resolución Ministerial No 802/2004 se creó el Programa de Inserción Laboral para Trabajadores con

3 Lastimosamente, Ios datos revelados por la Encuesta Nacional de Personas con Discapacidad en los años 2002/2003 y los del Censo del año 2010 son las últimas cifras oficiales vinculadas a la situación de las personas con discapacidad en nuestro país. Actualmente, el Instituto Nacional de Estadísticas y Censos (INDEC) está realizando una nueva encuesta nacional sobre la situación de las Personas con Discapacidad. Ver publicación: https://www. argentina.gob.ar/noticias/indec-estudio-nacional-sobre-la-poblacion-con-discapacidad. 
Discapacidad (PIL) dirigido al ámbito privado, y extendido en el año 2007 al ámbito público. El cual ofrece beneficios fiscales y previsionales para empresas, y ayuda económica en el pago de salarios para aquellos organismos que empleen trabajadores con discapacidad. De las 25.662 personas que se inscribieron en el registro de empleo del Ministerio de Trabajo entre 2010 y 2015, sólo han conseguido trabajo en el ámbito público 90, es decir, el 0,35\% (BLOGNA, T. 2016)

Numerosos académicos dedicados al estudio de la discapacidad como el ya citado Mike Oliver (1981), Víctor Finkelstein (1980), Colin Barnes (1996), Paul Abberley (1987), entre otros, desarrollaron el enfoque que encuentra al modelo de producción capitalista como el principal responsable de la exclusión económica y social de las personas con discapacidad tal como la conocemos hoy ${ }^{4}$. Contrariando los postulados sostenidos hasta el momento, los cuales la consideraron en un comienzo como un problema religioso, y posteriormente como un asunto estrictamente médico (PALACIOS, A. 2008).

\section{El capitalismo industrial como productor de discapacidad}

Siempre han existido personas con deficiencias físicas, cognitivas o sensoriales, sin embargo, su participación fue mutando de acuerdo a los distintos modos en que las sociedades organizaron sus sistemas de producción. ${ }^{5}$

4 "La economía, tanto mediante la actuación del mercado de trabajo como la organización social del trabajo, desempeña un papel clave en la producción de la categoría de discapacidad y en la determinación de las respuestas de la sociedad a las personas discapacitadas. Además, la opresión a la que estas se enfrentan tiene sus raíces en las estructuras económicas y sociales del capitalismo, que por sí mismas producen racismo, sexismo, homofobia, gerontología y discapacidad." (BARNES, C. 1996)

5 “El avance científico y tecnológico favorecerá la expansión de los Estados europeos más pujantes. Así será posible que entren en contacto regiones planetarias de las que apenas se tenía noticias. En ese contexto, entre los siglos XV y XVIII se configuro una organización política y económica del mundo cuya influencia se ira notando progresivamente sobre todas 
Al situarnos en la Europa preindustrial, advertimos que las personas con discapacidad, aun ocupando la grada más baja de la escala social, no estaban excluidas por completo del proceso productivo. (OLIVER, M. 1981; FILKENSTEIN, V. 1980; JOLY, E. 2007). Al respecto, Marta Russell (2002), expresa:

Las personas con discapacidad eran vistas como infrahumanas y, como muchos otros, sufrieron enormemente bajo condiciones extremadamente difíciles, pero la mayoría estaba integrada a sus comunidades. Algunos sobrevivieron realizando el trabajo que podían, en los campos o en la cocina. Algunos se convirtieron en artesanos habilidosos, dominando una actividad que, notablemente, les permitió trabajar a su propio ritmo.

El paso de una economía agraria y artesanal a una economía basada en la producción industrial y su consiguiente división técnica del trabajo ${ }^{6}$, implicó una modificación sustancial para este colectivo de trabajadores.

Los propietarios de los medios de producción, en función de maximizar sus ganancias, procuraron que los obreros generaran un mayor plusvalor asegurándose que la mayor parte de la jornada laboral consista en trabajo excedente. En este sentido, extendieron las jornadas, incorporaron nuevas tecnologías y asignaron ritmos más acelerados de producción. Todo aquel sospechado de no poder adaptarse a este escenario, era descartado. (MARX, C. 1867; JOLY, E. 2007)

Se encargaron de contratar solo a quienes consideraban capaces de realizar tareas repetitivas durante extensas jornadas laborales en condiciones inhumanas, lo que produjo ruinosos resultados. Al respecto señalaba Friedrich Engels en su obra "La situación de la clase obrera en Inglaterra" (1845):

\footnotetext{
las sociedades y economías locales. Desde este modo la escala de relaciones se "globaliza". (MEDICl, A.; PESCADER, C.; CATALANI, F. 2012)

6 Las palabras del industrial inglés, Richard Arkwright, refleja la situación de la época:" ...era difícil educar a los seres humanos para que renunciaran a sus desordenados e ineficientes hábitos de trabajo, para identificarse con la invariable regularidad de las máquinas automáticas" (BAUMAN, Z. 1998)
} 
¡He aquí, pues una buena lista de enfermedades, debidas únicamente a la odiosa codicia de la burguesía! Mujeres incapacitadas para la procreación, niños lisiados, hombres debilitados, miembros aplastados, generaciones enteras estropeadas; condenadas a la debilidad y la tisis, y todo ello, júnicamente para llenar la bolsa de la burguesía! En Manchester, se puede ver, aparte de numerosos lisiados, un gran número de mutilados; uno ha perdido todo el brazo o el antebrazo, otro un pie, aun otro la mitad de la pierna; tal parece que se halla uno en medio de un ejército que regresa de una campaña.

En este contexto comienza a utilizarse el concepto de "Discapacidad" entendido como la incapacidad para ser explotado con vistas a maximizar las ganancias de la clase capitalista (RUSSELL, M. 2002). Ante la velocidad y la disciplina cronométrica del proceso productivo fabril, las personas con alguna deficiencia comenzaron a encontrarse en grave desventaja. Se convirtieron en un problema social para el estado capitalista, que respondió con el aislamiento en diferentes instituciones médicas (OLIVER, M. 1998); se las encerró en lo que Foucault (1967) llamó "el gran confinamiento".

De esta manera, el flamante capitalismo industrial -y en función de sus requerimientos-, segregaba a los "aptos" de los "no-aptos", reduciendo la capacidad de cualquier individuo a la posibilidad de adaptarse al mecánico, repetitivo y veloz proceso productivo. "Vigilancia y disciplina, para aquellos cuyo trabajo podía ser explotado provechosamente; vigilancia $y$ confinamiento, para aquellos que el mercado no podía emplear lucrativamente" (RUSSELL, M. 2002). Así, la psicopatía capitalista, que no considera a las personas como tales sino como medio para sus fines (JAUREGUI, I. 2008), se paraba -y aún lo hace- frente a la cinta trasportadora, viendo pasar los productos -trabajadores-, y en un sosegado control de calidad descarto a los "dañados".

Las personas con discapacidad se convertían en el "daño colateral" del progreso económico, desechadas sin mediar palabra, sin importar sus reales aptitudes. Alcanzaba con ser 
portadoras del estigma (GOFFMAN, E. 2001), para decidir su descarte. Sobre esto volveré más adelante, puesto que es un fenómeno que aún perdura.

Los Estados - como garantes de la reproducción del capitalismo - instauraron la teoría de la tragedia personal con el fin de justificar la exclusión económica y social de este colectivo. Según ésta, la discapacidad es un hecho trágico que le ocurre a individuos aislados, de manera aleatoria. Mike Oliver (1998) explica con claridad la función ideológica que desempeñó -y aún desempeña- dicha teoría:

Al igual que la teoría del déficit para explicar el bajo rendimiento académico, o la enfermedad para explicar el comportamiento criminal, al igual que la debilidad de carácter como explicación de la pobreza y el desempleo $\mathrm{y}$, al igual que todas las otras teorías en las que se culpa a la víctima, la teoría de la tragedia personal sirvió para individualizar los problemas de la discapacidad y así dejar intactas las estructuras sociales y económicas.

Asimismo, la teoría de la tragedia personal -transformando lo social en individual-, es capaz de ocultar el innegable vínculo entre la desigualdad y la discapacidad; encubre una serie de factores políticos, sociales y económicos hondamente incapacitantes. Las desventajas corporales y cognitivas fruto de la desnutrición intrauterina y la malnutrición infantil, las discapacidades motrices causadas por las malas condiciones laborales, o aquellas producidas por la contaminación ambiental, solo por mencionar algunas.

En este sentido, la discapacidad se vuelve una herencia social (JOLY, E. 2007). Los datos revelados por el Informe Mundial de la Discapacidad son prueba de ello: el 80\% de las personas con discapacidad son pobres. Poseen menor acceso a la salud, la educación, el empleo, el transporte, o la información (OMS y BANCO MUNDIAL 2011).

Podemos decir, sin lugar a dudas, que la situación de las personas con discapacidad a nivel global, refleja el triunfo del 
capitalismo en su objetivo por garantizar su reproducción a escala sistémica (SCRIBANO, A. 2007).

\section{Las personas con discapacidad como inempleables}

La palabra desempleo ${ }^{7}$ con su prefijo "des", subraya una situación fuera de la norma. Sin embargo, para las personas con discapacidad, el desempleo ha sido un estado natural y permanente. Desde que el incipiente capitalismo industrial les dio la espalda, hasta nuestros días.

Aun peor es la situación actual, con fenómenos como el jobless growth (crecimiento económico sin empleo) o el joblose growth (crecimiento económico con pérdida de empleo); causado, entre otros motivos, por el rápido e incesante desarrollo tecnológico. La digitalización y la robotización de millones de trabajos emerge como una tendencia inevitable dejando a muchas personas sin un puesto de trabajo. Una investigación liderada por Daron Acemoglu (2016), economista y profesor del MIT, estima que desde 1990 a 2007 cada robot de fábrica destruyó seis puestos de trabajo. Significando unos 670.000 trabajos perdidos durante los años analizados, solo en EE. UU.

Este contexto no hace otra cosa que disminuir aún más las posibilidades de que las personas con discapacidad encuentren lugares disponibles en el competitivo mercado laboral.

Ayer y hoy, las personas con discapacidad han sido y son superfluas $^{8}$ frente a la óptica del capitalismo como modelo

\footnotetext{
7 “El desempleo, tal y como lo conocemos ahora, no ha existido desde siempre(...) En inglés, el término "unenployment» aparece en el diccionario con su significado actual a finales del siglo XIX. De acuerdo con el New Dictionary of Historical Principles, el término estaba en uso desde 1600, pero con un significado distinto: efectivamente, se refería a hombres y cosas inutilizadas. En cambio, para definir la condición de las personas sin trabajo se aplicaba el término "idleness», y no es casual que signifique no sólo desempleo sino también ocio. En definitiva, para definir al desempleado se aplicaba un término implícitamente despreciativo. (Murray, 1908)." (PUGLIESE, E. 2000)
}

8 "Ser "superfluo" significa ser supernumerario, innecesario, carente de uso — sean cuales fueren las necesidades y los usos que establecen el patrón de utilidad e indispensabilidad—. 
histórico y social de producción. Puesto que los empresarios y encargados de seleccionar trabajadores suelen considerar a las personas con discapacidad como un grupo de alto riesgo incapaz de alcanzar niveles de productividad normales; a pesar de pruebas que demuestran lo contrario (BORSAY, A. 2008).

Si tuviéramos que definir a una persona sin discapacidad en términos geométricos, frente a una entrevista laboral, podríamos decir que es como un poliedro de veinte caras - icosaedro-, y cada una de ellas representa un aspecto de sí. Podrían evaluar su desempeño de acuerdo a la capacidad para trabajar en forma grupal, si es resolutivo, las dotes para el liderazgo, su presencia, por mencionar algunos. Sin embargo, las personas con discapacidad, parecieran cargar con la etiqueta (BECKER, H. 2009) de "inempleable", sin siquiera entrar dentro de las posibilidades de ser entrevistados. La deficiencia actúa como velo para todo lo demás. En una encuesta realizada en Francia se comprobó que menos de un $2 \%$ de aquellos que hicieron mención de una discapacidad en el CV fueron convocados para una entrevista (OIT, 2003). No tener siquiera la posibilidad de ser entrevistados es muestra ineludible de la estigmatización que sufre esta minoría. Existen estudios que han demostrado las virtudes de la inmediación entre las personas con discapacidad y los encargados de reclutar personal, señalando que influye significativamente en el proceso final de selección; demostrando que la ausencia de contacto modifica negativamente las percepciones y los juicios (MACAN, T. y HAYES, T. 1995).

Esta estigmatización, de acuerdo a lo expresado por Link y Phelan (2001) es conformada a través de cuatro componentes: el etiquetamiento de las diferencias humanas; la vinculación

\footnotetext{
Los otros no te necesitan; pueden arreglárselas igual de bien, si no mejor, sin ti. No existe razón palmaria para tu presencia ni obvia justificación para tu reivindicación del derecho de seguir ahí. Que te declaren superfluo significa haber sido desechado por ser desechable, cual botella de plástico vacía y no retornable o jeringuilla usada; una mercancía poco atractiva sin compradores o un producto inferior o manchado, carente de utilidad, retirado de la cadena de montaje por los inspectores de calidad. (BAUMAN, Z. 2005)"
} 
de las personas etiquetadas con características indeseables; la separación de "ellos" (las personas estigmatizadas) de "nosotros"; y la consiguiente pérdida de estatus y discriminación.

A esta creencia por parte de los empleadores y encargados de seleccionar trabajadores, mediante la cual sostienen que las personas con discapacidad no se encuentran preparadas para realizar la mayor parte de los trabajos, debemos sumarle la falta de confianza por parte de las mismas personas con discapacidad (PALACIOS, A. 2008). Tal como señalan Saxton y Howe (1987): "Al ser el blanco de suposiciones incorrectas, nociones estereotipadas y mensajes que invalidan quienes somos comenzamos a creer que son ciertos; interiorizamos la opresión".

Al mismo tiempo, debemos decir que el desempleo no es un perene yerro por parte de la economía capitalista. Por el contrario, es inherente a ella (KEYNES, J. M. 1936; MARX, C. 1867).

Hace décadas que la teoría económica dominante señala la necesidad de sostener un umbral de desempleo capaz de mantener salarios bajos, y así evitar la inflación. Así, racionalizan el desempleo, pero siempre sin hacer mención acerca del sistema económico o a las relaciones sociales que lo crean. Numerosa evidencia empírica demuestra la correlación existente entre los niveles de salarios y el desempleo. Cuanto más amplia es la masa de reserva laboral activa, será mayor la competencia por los empleos, lo cual mantiene los salarios a niveles bajos protegiendo los márgenes de beneficio de las compañías (RUSSELL, M. 2008). El economista James Galbraith (1998) explica con simpleza que "en periodos en los que el nivel de empleo es alto, los débiles ganan terreno sobre los más fuertes; en periodos de alto nivel de desempleo, son los fuertes los que ganan terreno sobre los débiles".

El desempleo deliberado, sumado a los prejuicios y mitos que los vinculan con la improductividad, laceran las posibilidades de las personas con discapacidad para encontrar trabajo. 


\section{Reflexiones finales}

El primero de los Principios Generales de la Convención, escritos en el artículo 3, reza: "El respeto de la dignidad inherente, la autonomía individual, incluida la libertad de tomar las propias decisiones, y la independencia de las personas".

En su Preámbulo, la Convención sobre los Derechos de las Personas con Discapacidad, manifiesta la importancia que para las personas con discapacidad reviste su autonomía e independencia individual. Lo que resulta absolutamente inalcanzable si no son admitidos en el mercado laboral, por lo que reconoce expresamente el derecho a trabajar en su Art. 27. Asimismo, términos como "trabajo", "trabajar", "empleo", "emplear", y "mercado laboral" fueron mencionados un total de 29 veces a lo largo de todo el texto, demostrando la relevancia y el carácter transversal de este derecho.

Sin embargo, el derecho a tener la oportunidad de ganarse la vida mediante un trabajo (ONU 2006) seguirá siendo tan solo una expresión de deseo en tanto el capitalismo global continúe necesitando de desempleados forzosos para funcionar.

Cuando las personas con derechos no tienen el poder y los recursos para competir de la manera adecuada, los derechos no pueden hacer más que reforzar el statu quo, debido a que aquellos que quedan sin poder no pueden hacer otra cosa que reclamos esporádicos o simbólicos. (YOUNG, D. y QUIBELL, R. 2000)

A pesar de lo señalado, las personas con discapacidad tienen alternativa: autoorganización y acción directa. La sugerencia de Safilios-Rotchschild realizada en el año 1976 es preciso reproducirla aún hoy:

Puede ser el momento indicado para que las personas con discapacidad generen un movimiento social a imagen de los ejemplos -al menos parcialmente exitosos- del movimiento negro y del movimiento de la mujer. (SAFILIOS-ROTHSCHILD, C. 1976) 
Construyendo una identidad política como grupo oprimido (SHAKESPEARE, T. 2008), con potencial capaz de visibilizar los reales motivos de su exclusión económica y social, e incorporando sus demandas a la agenda pública.

\section{Referencias}

ACEMOGLU, D. y RESTREPO, P. (2016). "The Race Between Machine and Man: Implications of Technology for Growth, Factor Shares and Employment", NBER working paper No. 22252

BARNES, C. (1998). "Las teorías de la discapacidad y los orígenes de la opresión de las personas discapacitadas en la sociedad occidental". En Barton, Len [comp.], Discapacidad y sociedad, Madrid: Ediciones Morata.

BAUMAN, Z. (1998). Trabajo, consumismo y nuevos pobres. Gedisa, Barcelona.

BAUMAN, Z. (2005). Vidas desperdiciadas. La modernidad y sus parias. Paidós, Barcelona.

BECKER, H. (2009). Outsiders. Hacia una sociología de la desviación. Buenos Aires: Siglo XXI.

BLOGNA, T. (2008): El derecho humano al empleo de las Personas con discapacidad: análisis de políticas públicas en el ámbito público nacional de Argentina. II Simposio Internacional del Observatorio de la Discapacidad. Políticas públicas, ideologías y modos de abordaje de la discapacidad en el marco de las Ciencias Sociales.

BORSAY, A. (2008). ¿Problema personal o asunto público? Hacia un modelo de políticas para las personas con discapacidades físicas y mentales. En: Barton, Len, comp. (2008) Superar las barreras de la discapacidad. Madrid: Morata.

CELS (2017). Situación de las personas con discapacidad en Argentina.

ENGELS, F. (1845). situación de la clase obrera en Inglaterra. Editorial Futuro, 1965, Buenos Aires.

FERRANTE, C. (2015). Discapacidad y mendicidad en la era de la Convención: ¿Postal del pasado? . Convergencia, revista de ciencias sociales, 152. 
FINKELSTEIN, V. (1980). Attitudes and Disabled People, Nueva York, World Rehabilitation Fund.

FOUCAULT, M. (1976) Madness and Civilization: A History of Insanity in the Age of Reason. New York, Pantheon.

FRIEDMAN, M. (1968). The Role of Monetary Policy. American Economic Review, 58 (1), 1-17.

GALBRAITH, J. (1998). Created Unequal: the crisis in American pay, Nueva York, Simon \& Schuster.

JAUREGUI, I. (2008). Psicopatía: Pandemia de la modernidad. Nómadas. Revista Crítica de Ciencias Sociales y Jurídicas.

KEYNES, J.M. (1936). The General Theory of Employment, Interest and Money. Nueva York: Harcourt and Brace.

LINK, B. y PHELAN, J. (2001). On the nature and consequences of stigma. Annual Review of Sociology; 27: 363-385.

MACAN, T. y HAYES, T. (1995). Both sides of the employment interview interaction: Perceptions of interviewers and applicants with disabilities.

MARX, C. (1867). El Capital: Crítica de la economía política. Tomo I. Fondo de Cultura Económica. México. 2001

MEDICI, A.; PESCADER, C.; CATALANI, F. (2012). Derecho Político Actual: temas y problemas. Santa Rosa, Universidad Nacional de La Pampa.

OLIVER, M. (1983). Social Work with Disabled People. Basingstoke. Macmillan.

OLIVER, M. (1986). "Social policy and disability: some theoretical issues", Disability, Handicap \& Society, Vol. 1.

OLIVER, M. (1998). ¿Una sociología de la discapacidad o una sociología discapacitada? En Barton, Len [comp.], Discapacidad y sociedad, Madrid: Ediciones Morata.

PALACIOS, A. (2008). El modelo social de discapacidad: orígenes, caracterización y plasmación en la Convención Internacional sobre los Derechos de las Personas con Discapacidad. Madrid. Cermi Colección $\mathrm{N}^{\circ} 36$.

PUGLIESE, E. (2000). "Qué es el desempleo". En Política y Sociedad, No. 34, pp. 59-6

RICARDO, D. (1817). "Sobre los principios de la economía política y de la tributación”. John Murray, Inglaterra. 
RUSSELL, M. (2002). The political economy of disablement, 2002. Marta Russell, The political economy of disablement, Dollars and Sense, Boston.

RUSSELL, M. (2008). "Lo que no pueden hacer los derechos civiles en el ámbito de la discapacidad. Empleo y economía política". En Barton, Len [comp.], Superar las barreras de la discapacidad, Madrid: Morata.

SAFILIOS-ROTHSCHILD, C. (1976). "Disabled persons' self-definitions and their implications for rehabilitation". En: G. L. ALBRECHT The Sociology of Physical Disability and Rehabilitation, Pittsburgh, PA, University of Pittsburgh Press.

SAXTON, M. y HOWE, F. (1987). With wings: an anthology of literature by and about women with disabilities, Nueva York, Feminist Press.

SCRIBANO, A. (2007). "La sociedad hecha callo: conflictividad, dolor social y regulación de las sensaciones", en Scribano, Adrián [comp.], Mapeando Interiores. Cuerpo, Conflicto y Sensaciones, Córdoba: CEA, UNC, Jorge Sarmiento Editor.

SHAKESPEARE, T. (2008) La autoorganización de las personas con discapacidad: ¿Un nuevo movimiento social? En: Barton, Len, comp. (2008) Superar las barreras de la discapacidad. Madrid: Morata.

UPIAS (1976). Fundamental Principles of Disability, Londres: Union of Physucally ground of culture and self.

YOUNG, D. y QUIBELL, R. (2000). "Why rights are never enough", Disability \& Society.

\section{Documentos de Organismos Internacionales}

OEA (1999). Convención Interamericana para la eliminación de todas las formas de discriminación contra las personas con discapacidad.

OIT (2003). Discriminación por razones de discapacidad, Resumen analítico, Declaración relativa a los Principios y Derechos Fundamentales en el Trabajo, Trabajar en Libertad.

OIT (2008). Convenio sobre la readaptación profesional y el empleo de las Personas Inválidas.

OMS, Banco Mundial (2011). Informe mundial sobre la discapacidad. 
ONU (1948). Declaración Universal de los Derechos Humanos. ONU (1966). Pacto Internacional de Derechos Civiles y Políticos. ONU (1966). Pacto Internacional de Derechos Económicos, Sociales y Culturales.

ONU (2006). Convención Internacional sobre los Derechos de las Personas con Discapacidad, ONU (2006)

\section{Leyes y Resoluciones}

Ley $\mathrm{N}^{\mathrm{o}} 22.431$

Ley $\mathrm{N}^{\circ} 25.689$

Ley $\mathrm{N}^{\mathrm{o}} 26.378$

Resolución Ministerial $N^{o}$ 802/2004 del Ministerio de Trabajo, Empleo y Seguridad Social. 